\title{
Planejamento em Saúde
}

\author{
Health planning
}

Planificación de la salud

Antonio José Costa CARDOSO ${ }^{1}$

Sérgio R. SCHIERHOLT ${ }^{2}$

Resumo: Esse texto pretendeu subsidiar aula sobre Planejamento e Avaliação em Saúde para os Analistas Técnicos de Políticas Sociais lotados no Ministério da Saúde (MS), na perspectiva de promover uma maior compreensão dos antecedentes históricos do planejamento em saúde no Brasil e na América Latina, do referencial teórico metodológico do planejamento estratégico e participativo, e refletir sobre os avanços e desafios que se apresentam no atual contexto de construção do Sistema Único de Saúde (SUS). Neste sentido, foi estruturado na perspectiva de responder a três questões orientadoras: 1) Como tem se dado esse processo de coordenação do Planejamento Estratégico Nacional no âmbito do SUS, em cooperação técnica com os Estados, Municípios e Distrito Federal? 2) Quais são as tecnologias de gestão e planejamento em saúde adotadas pelo MS para conduzir esses processos de forma integrada? 3) Como se dá o gerenciamento das ações no MS? Como os planos, projetos e programas são monitorados pelas equipes responsáveis? Palavras-Chaves: Reforma Sanitária; Política de Saúde; Planejamento em Saúde; Avaliação em Saúde; Monitoramento em Saúde.

Abstract: This text was intended to subsidize education on health planning and evaluation for Technical analysts crowded social policies in the Ministry of health (MS), with a view to promoting greater understanding of the historical background of health planning in Brazil and in Latin America, the theoretical methodology of strategic planning and participatory, and reflect on the advances and challenges in the current context of constructing the Sistema Único de Saúde (SUS). In this sense, it was structured in order to answer three questions: 1) As has given this process of coordination of National Strategic Planning within the SUS, in technical cooperation with the States, Municipalities and the Federal District? 2) What are the management technologies and planning in health adopted by MS to drive these processes in an integrated manner? 3) How is the stock management in MS? How plans, projects and programs are monitored?

\footnotetext{
1 Médico, Doutor em Saúde Pública, Professor Adjunto do Departamento de Saúde Coletiva da Faculdade de Ciências da Saúde da UnB, coordenador da Graduação em Gestão em Saúde Coletiva. Contato: antoniojccardoso@gmail.com 2 Faculdade da Ceilândia da Universidade de Brasília - sergiors@ unb.br 
Key Words: Health policy; Health planning; Health assessment; Health monitoring.

Resumen: Este texto fue destinado a subsidiar la educación en materia de evaluación y planificación de la salud para los analistas técnicos lleno las políticas sociales en el Ministerio de salud (MS), con miras a promover una mayor comprensión de los antecedentes históricos de la planificación de la salud en Brasil y en América Latina, la metodología teórica de la planificación estratégica y participativa y reflexionar sobre los avances y desafios en el contexto actual de la construcción del Sistema Único de Saúde (SUS). En este sentido, se estructuró con el fin de responder a tres preguntas: 1) ¿Que ha dado lo proceso de coordina-Planejamento em Saúde Health planning Planificación de la saludción de la planificación estratégica nacional del SUS, en cooperación con los Estados, municipios y Distrito Federal? 2) ¿Cuáles son las tecnologías de gestión y planificación en salud adoptada para conducir estos procesos de forma integrada? 3) ¿Cómo es la gestión en MS? ¿Como los planes, programas y proyectos son supervisados? Palabras Clave: Política de salud; Planificación de la salud; Evaluación de la salud; Vigilancia de la salud.

\section{Histórico do Planejamento em Saúde}

Paim1 aponta as origens da ideologia e da prática do planejamento no Brasil entre 1930 e 1945 (Estado Novo), quando se desenvolvia uma "política econômica nacionalista", embora "de forma desigual e fragmentária, segundo as possibilidades apresentadas pelo sistema político-administrativo e os interesses predominantes do setor privado da economia”.

Segundo Paim1, entretanto, "somente no governo Kubitscheck (1956-1960) é que, através do Programa de Metas, se realiza uma política econômica relativamente planificada”.

Quanto aos setores sociais, só apareceram no âmbito do planejamento federal após 1964, no regime autoritário que passou a dirigir o Estado brasileiro, em parte, como resposta às "preocupações políticas dos governantes..., em face da revolução socialista em Cuba. (...) Portanto, o planejamento social autoritário que se instala no país é fruto desse regime e desse Estado. Não poderia ser diferente. (...) O seu caráter autoritário ou democrático não parece depender de nenhuma fatalidade histórica nem de uma perversão da ideologia tecnocrática".1

Segundo Paim1: "Esse estilo de planejamento é que vai caracterizar os planos da ditadura. (...) Somente com o esgotamento do 'milagre' e com a crise de legitimidade evidenciada pela derrota do governo nas eleições de 1974 - que teve um caráter plebiscitário -, foi proposto o II PND [Plano Nacional de Desenvolvimento] acenando para 'políticas redistributivas"”.

Na medida em que o autoritarismo se debilitava, "a questão social voltava à tona".

Também no âmbito da saúde pública brasileira, ainda que possam ser identificadas iniciativas pioneiras antes de 1974, foi tardia a instituição de políticas planificadas. 
“O caráter essencial assumido pelas necessidades de saúde, de um lado, e, de outro lado, a acentuada desigualdade na distribuição social de sua satisfação, especialmente nos países do terceiro mundo, explicam, sinteticamente, a transcendência desse debate. A assimetria 'produção-consumo' dos 'bens' de saúde, que em outro setor qualquer da vida social poderia passar por fenômeno de menor relevância, uma 'anomia' localizada, assume aqui caráter dramático. Devido à importância nuclear dessas práticas de saúde na constituição material e simbólica das sociedades capitalistas, problemas nesta esfera sempre extrapolam os setores mais imediatamente envolvidos, interessando ao conjunto das forças sociais". 2

Mesmo no pós-74, estas políticas públicas de saúde abstraíam-se das condições para sua implementação, caracterizando-se pelo seu caráter autoritário e "nitidamente vertical”, realizandose através de campanhas sanitárias e programas especiais do Ministério da Saúde (MS) e, mais, portarias e ordens de serviço do Ministério da Assistência e Previdência Social.

Registre-se, aqui, o insucesso dessas iniciativas, com destaque para a "implosão" do PREVSAÚDE (Programa Nacional de Serviços Básicos de Saúde), esta que se constituiu na "mais exuberante das iniciativas malogradas de planejamento autoritário de saúde no Brasil”.1

Com o advento da democracia, imaginavam-se superadas as dificuldades identificadas no processo de planificação, muitas vezes atribuídas a uma suposta "crise do planejamento autoritário". De fato, é no contexto histórico da redemocratização que surgem momentos de produção teóricometodológica no campo disciplinar da planificação em saúde e aparecem oportunidades para sua utilização. Todavia, passados mais de vinte anos da promulgação da Constituição Federal de 1988, pode-se dizer que a institucionalização do planejamento nas organizações de saúde permanece como um desafio à teoria da planificação e à gestão dos sistemas e serviços de saúde no Brasill.

\section{Problemas e desafios}

O planejamento desenvolvido na América Latina durante a maior parte das cinco últimas décadas foi vítima de vários mal-entendidos que geraram sucessivos períodos de euforia, decepção, crise e recuperação parcial. Em suma, o principal mal-entendido consistiu em procurar utilizar a ferramenta do Planejamento Normativo, que se revelou sumamente útil e eficaz em situações de poder concentrado, para decidir problemas econômicos de apropriação e alocação de recursos e de distribuição de produtos em situações de poder compartilhado.

Na América Latina, a grande corrente do pensamento gerada em conseqüência da crítica ao Planejamento Normativo pode ser englobada sob a denominação genérica de Planejamento Estratégico e está representado principalmente pelos pensamentos de Carlos Matus e Mario Testa. A característica definidora desta tendência é sua explícita incorporação do político, não como marco referencial, mas como parte de seu objeto específico de trabalho.

O Planejamento tem sido designado, comumente, como um método, uma técnica, uma ferramenta 
de gestão: "uma técnica gerencial que procura, por meio da análise do ambiente de uma organização, criar consciência de suas oportunidades e ameaças, assim como de seus pontos fortes e fracos, e, a partir daí, traçar os rumos ou direção que essa organização deverá seguir para aproveitar as oportunidades, potencializar seus pontos fortes e minimizar ameaças e riscos". 4

Seu produto é o "Plano Estratégico", para um horizonte de tempo determinado.

Invertendo os termos da equação de muitas das teorias da administração, Matus compreende a Gestão como um momento (tático-operacional) do processo, mais amplo, de Planejamento, e não o planejamento como método, ferramenta, instrumento da Gestão.

A depender do grau de formalização do "cálculo que precede e preside a ação", o seu produto pode ou não estar estruturado na forma de um "Livro-Plano".

Com raízes no marxismo, Carlos Matus procedeu a uma aguda crítica ao Planejamento Normativo, construindo sua proposta sobre a noção de "situação", definida como sendo o lugar social onde está situado o ator que planeja e a ação, compondo uma "totalidade complexa". O Planejamento é, para Matus, um traçado de mudanças situacionais em um contexto de forças sociais oponentes, portanto "ação estratégica".

O ponto de partida é uma situação inicial ( $\mathrm{Si}$ ) e uma situação-objetivo (So) à qual pode-se chegar por diferentes trajetórias que implicam situações intermediárias diversas. Sobre estas bases, Matus analisa as condições para a construção da viabilidade política. 5

Pode-se dizer que, para Matus, todo processo de planejamento tem a pretensão de ampliar a "capacidade de governo" (conjunto de destrezas, experiências, habilidades, teorias e métodos de direção que uma equipe de governo dispõe), dar-lhe "direcionalidade" e, por esta via, ampliar a "governabilidade" (relação entre as variáveis que controla e que não controla) da organização, visando o cumprimento de algum "projeto de governo", o que corresponde ao "triângulo de governo".

Mário Testa, cuja referência é o processo político argentino, embora considere a intenção de Matus "cheia de originalidade e atitude construtiva", acredita "que Matus substitui a normatividade técnico-econômica por uma normatividade política, o que reduz a eficácia de sua proposta" (1992:108). A principal crítica de Testa a Matus é, fundamentalmente, uma crítica histórica porque, apesar de concordar com a necessidade de "continuidade entre história e Plano", não compartilha da visão de Matus de se colocar em posição de "dirigir as forças consideradas progressistas, entendendo que estas não estão, de fato, bem identificadas". 6

O planejamento deve resolver, na opinião de Matus, quatro grandes questões cujo enfrentamento corresponde a quatro "momentos" de um "processo contínuo", apresentados no Quadro 1, a seguir. Estes Momentos do PES não correspondem a Etapas: pode-se adentrar no planejamento pelo seu 
momento Tático-Operacional, por exemplo, avaliando ações já finalizadas ou em desenvolvimento.

Quadro 1 - Momenos de Planejameno Estratégico Situacioanl (PES)

\begin{tabular}{|l|l|}
\hline \multicolumn{1}{|c|}{ Questões a serem enfrentadas } & Momentos do PES \\
\hline $\begin{array}{l}\text { 1 0 Qual a nossa situação (“a reealidade a partir de var- } \\
\text { ias perspectivas situacionais", "explicações situacionais } \\
\text { por problemas" e "explicações situacionais de síntese"? }\end{array}$ & Momento explicativo: como foi, é, tende a ser? \\
\hline $\begin{array}{l}\text { Para onde queremos ir? Quais as metas a atengir? O que } \\
\text { devo fazer? }\end{array}$ & Momento normativo: como deve ser? \\
\hline $\begin{array}{l}\text { Qual a viabilidadedo nosso Plano (considerando-se os } \\
\text { dafios representados pelas restrições de recursos e pelos } \\
\text { obstáculos colocados) }\end{array}$ & Momen estratégic: O que pode ser? \\
\hline $\begin{array}{l}\text { O que devo fazer e posso fazer hoje, e todos os } \\
\text { dias quando forem hoje, para que avancemos } \\
\text { em direção a nossa situação-objetivo? }\end{array}$ & Momento tático-operacional: o que fazer? \\
\hline
\end{tabular}

\section{Principais usos e instrumentos}

Na prática dos serviços, Teixeira3 destaca que o processo de construção do SUS ampliou e diversificou os objetos e sujeitos da prática de planejamento, podendo-se identificar, pelo menos, três espaços privilegiados de exercício do planejamento, que podem ser compreendidos como integrantes de um "sistema de planejamento em saúde": 1) a área de formulação de políticas voltadas para o enfrentamento de problemas específicos ou para o atendimento de necessidades de grupos específicos da população; 2) o campo do planejamento de sistemas de saúde, impulsionada pela implementação das Normas Operacionais (NOBS, NOAS e Pacto pela Saúde); e, 3) a área da programação, com a tendência a integrar os "programas especiais" com a "programação local" (“ações programáticas") no âmbito de sistemas locais de saúde.

No âmbito do Ministério da Saúde, o Sistema de Planejamento precisa responder, necessariamente, a dois processos institucionais: um primeiro interno ao SUS, vertical em relação aos demais níveis de governo do sistema; e outro trans-setorial, transversal em relação aos outros setores do mesmo nível de governo (federal).

Desde as Leis 8080 e 8142/1990 estão definidas as responsabilidades quanto ao processo de planejamento do SUS, a lógica de formulação dos planos e sua aplicabilidade. A Lei 8.080/90 atribui à direção nacional do SUS a responsabilidade de "elaborar o planejamento estratégico nacional no âmbito do SUS em cooperação com os estados, municípios e o Distrito Federal” (inciso XVIII do Art. 16).

No seu Art. 37, a Lei atribui ao Conselho Nacional de Saúde (CNS) a responsabilidade pelo estabelecimento de diretrizes para a elaboração dos planos de saúde, “em função das características 
epidemiológicas e da organização dos serviços". Estabelece ainda que o planejamento será ascendente, do nível local até o federal, compatibilizando-se as necessidades da política de saúde com a disponibilidade de recursos. A mesma Lei estabelece que "os planos de saúde serão a base das atividades e programações de cada nível de direção", estando vedada "transferência de recursos para o financiamento de ações não previstas nos planos", sendo responsabilidade do MS, por meio de seu sistema de auditoria, o "acompanhamento da aplicação dos recursos" repassados para estados e municípios.

A Lei 8.142/90 estabelece que o plano de saúde e o relatório de gestão são peças imprescindíveis a esse controle.

Após as LOS, merecem destaque as Portarias 548/2001, 399/2006 e 699/2006. A primeira aprova106 // Rev Tempus Actas Saúde as “Orientações Federais para a Elaboração e Aplicação da Agenda de Saúde, do Plano de Saúde, dos Quadros de Metas e do Relatório de Gestão como Instrumentos de Gestão do SUS”. A segunda “divulga o Pacto pela Saúde 2006 e aprova as Diretrizes Operacionais do referido pacto", e a terceira "regulamenta as Diretrizes Operacionais dos Pactos pela Vida e de Gestão".

No que se refere ao planejamento, o Pacto de Gestão estabelece cinco itens a serem pactuados:

(i) "adoção das necessidades de saúde da população como critério";

(ii) "integração dos instrumentos de planejamento";

(iii) "institucionalização e fortalecimento do PLANEJASUS (...) como instrumento estratégico de gestão do SUS"; (iv) "adoção de instrumentos de planejamento a serem adotados pelas três esferas de gestão";

(v) "cooperação entre as três esferas de gestão".

O Pacto estabelece a condução de "processo permanente de planejamento participativo e integrado, de base local e ascendente, orientado por problemas e necessidades em saúde" como responsabilidade comum aos entes federados, e define o Plano de Saúde, a Programação Anual de Saúde e o Relatório de Gestão como seus principais instrumentos de planejamento e gestão:

Planos de Saúde - O PlanejaSUS considera-o como o instrumento que, a partir de uma análise situacional, apresenta as intenções e resultados a serem buscados no período de quatro anos, expressos em objetivos, diretrizes e metas. Resumindo, o Plano de saúde deve ser a caracterização das políticas, dos compromissos e das prioridades de saúde no município, estado e união. É a base para a execução, acompanhamento, avaliação e gestão do sistema único de saúde.

Programação anual de Saúde- O horizonte temporal da Programação Anual de Saúde (PAS) 
coincide com o período definido para o exercício orçamentário, ou seja, um ano calendário. Portanto, as bases legais para sua elaboração são a Lei de Diretrizes Orçamentárias - LDO e Lei Orçamentária Anual - LOA. O propósito da programação é determinar um conjunto de ações que permita concretizar os objetivos definidos no Plano de Saúde, a partir da negociação e formalização de pactos ente os gestores das três esferas de governo.

Relatório Anual de Gestão - O Relatório Anual de Gestão (RAG) apresenta o desempenho da execução das ações no cumprimento das metas da Programação Anual, além de fornecer as bases para o ajusto do Plano e indicar os rumos para o ano seguinte. Esse relatório também deve ser aprovado pelo seu respectivo conselho de saúde após amplo debate com os seus segmentos.

\section{COMENTÁRIOS FINAIS}

Vimos que o Planejamento é, para Matus, um traçado de mudanças situacionais em um contexto de forças sociais oponentes, portanto "ação estratégica".

O ponto de partida é uma situação inicial ( $\mathrm{Si}$ ) e uma situação-objetivo (So) à qual pode-se chegar por diferentes trajetórias que implicam situações intermediárias diversas. Sobre estas bases, Matus (2003) analisa as condições para a construção da viabilidade política.

Cabe lembrar, como fizeram Paim \& Almeida Filho7 que "os sujeitos sociais encontram-se presentes em todos os 'momentos' do processo de trabalho: objeto, atividades, relações técnicas e sociais, meios de trabalho, além do próprio agente". Daí conceder-se grande ênfase à ação comunicativa, propondo-se a "administração da incerteza" como o núcleo central da condução dos processos de planejamento.

Numa sociedade democrática a viabilidade de todo e qualquer processo de mudança organizacional depende da abertura de processos intersubjetivos de "criação e recriação de acordos, de pactos, sempre conjunturais e transitórios". 8 Aparentemente, e este corresponde ao maior desafio do planejamento, tal mudança depende da compatibilização das exigências de uma multiplicidade de sujeitos diferenciados quanto a desejos, visões de mundo e interesses. Perguntar sobre os limites e possibilidades de construção de projetos coletivos é perguntar sobre os limites e possibilidades de se viver e trabalhar em grupo, o que remete à ambivalência que os indivíduos experimentam na relação com o grupo: satisfação de necessidades, mas também medos primitivos e frustração. Como regular tais processos, marcados pela ambigüidade, ambivalência e contradição? Repetindo Paim1:

“a planificação não faz a revolução. Também não emancipa por si mesma, ainda que amplie espaços para a constituição de sujeitos coletivos. Apenas informa, forma, formaliza...(...) O coração da crise da planificação, conseqüentemente, não parece estar na sua teoria, nos seus métodos e em suas técnicas, mas no Estado, na sociedade, na política.(...) Em vez de reforçar a encruzilhada ou 
de aprisionar-se no triângulo de governo matusiano, por que não triangular a produção teórica, a experiência técnico-institucional e a militância para, considerando o 'postulado da coerência', fazer História?". 1

\section{REFERÊNCIAS BIBLIOGRÁFICAS}

1 - PAIM J. Saúde, Política e Reforma Sanitária. Salvador, UFBA, 2002.

2 - AYRES JRCM. Epidemiologia e emancipação. São Paulo/Rio de Janeiro, HUCITEC/ ABRASCO, 2002.

3 - TEIXEIRA CF. Planejamento em saúde no Brasil : Sujeitos e Práticas . Salvador, ISC/ UFBA, 2003, 7 p (documento eletrônico).

4 - PORTO, C. Introdução ao planejamento estrat égico corporativo . Brasília: Macroplan Prospectiva e Estratégia, 1998.

5 - MATUS C. FUNDAMENTOS DO PLANEJAMENTO SITUACIONAL in Planejamento e programação em saúde: um enfoque estratégico. Rivera, FJU. (Org.). São Paulo/Rio de Janeiro: Cortez/ ABRASCO, 1989: 107-125.

6 - TeStA M. TENDÊnCiAs EM PlaneJAmEnto in Pensar em Saúde. Porto Alegre: ABRASCO, 1992: 89-128.

7 - PAIM J, ALMEIDA-FILHO N. A crise da Saúde Pública e a utopia da Saúde Coletiva . Salvador, Casa da Qualidade Editora, 2000.

8 - SÁ, M. C. SUBJETIVIDAdE E PROJETOS COLETIVOS: MAL-ESTAR E GOVERNABILIDADE NAS ORGANIZAÇÕES DE SAÚDE. Ciência \& Saúde Coletiva, Rio de Janeiro, 6(1):151-164, 2001.

Artigo apresentado em 12/12/13

Artigo aprovado em 16/03/14

Artigo publicado no sistema: 28/03/14 